\title{
Трепетание предсердий у детей младшего возраста
}

\author{
Мешкова М. С. ${ }^{1}$, Доронин А. В. ${ }^{2}$, Ханенова В. А. ${ }^{1}$, Руденко Н. Н. ${ }^{2}$ \\ ${ }^{1}$ ГУ «Научно-практический медицинский центр детской кардиологии \\ и кардиохирургии МЗ Украины» (Киев) \\ ${ }^{2}$ Национальная медицинская академия последипломного образования имени П. Л. Шупика (Киев)
}

\begin{abstract}
В статье анализируется собственный опыт лечения трепетания предсердий у детей младшего возраста (до 6 лет).

В исследуемую группу вошли 18 последовательных пациентов. У всех пациентов был восстановлен синусовый ритм путем медикаментозной или электрической кардиоверсии. У $10(55,6 \%)$ пациентов была выполнена медикаментозная кардиоверсия, у $5(27,8 \%)$ - отсроченная и у $3(16,7 \%)$ - срочная электроимпульсная терапия. У $2(11,1 \%)$ пациентов возник однократный рецидив аритмии после отмены антиаритмической терапии. У одного $(5,6 \%)$ пациента с неоднократно рецидивирующей аритмией в возрасте 4 лет 9 месяцев (вес 18 кг) была выполнена успешная радиочастотная катетерная абляция кавотрикуспидального перешейка.
\end{abstract}

Осложнений лечения не было. В настоящее время ни у одного пациента из группы наблюдения без антиаритмической терапии рецидива ТП нет.

Ключевые слова: дети, аритмии, трепетание предсердий, лечение.

Трепетание предсердий (ТП) - аритмия, которая редко встречается у детей в возрасте до 6 лет, не оперированных по поводу врожденного порока сердца [1]. Это затрудняет изучение причин возникновения, клинического течения и тактики лечения трепетания предсердий у детей этой возрастной группы. ТП составляет всего до 5\% тахиаритмий у детей младшего возраста [2]. В связи с этим в доступной литературе встречается ограниченное количество исследований на небольших группах пациентов, при этом не существует единого подхода к их лечению и определению дальнейшего прогноза [3-6]. Имеющиеся рекомендации по лечению таких детей в основном экстраполированы с исследований, проводившихся у взрослых пациентов.

Цель исследования - проанализировать наш опыт лечения трепетания предсердий у детей младшего возраста.

Материалы и методы. В исследуемую группу вошли 18 детей младше 6 лет, которые проходили стационарное лечение по поводу трепетания предсердий в ГУ «Научно-практический медицинский центр детской кардиологии и кардиохирургии» МЗ Украины с 2007 по 2016 г. и не были прооперированы по поводу врожденного порока сердца. Из них мальчиков было $11(61,1 \%)$, девочек - 7 (39,9\%). Средний возраст составил 2,6 года ( $\pm 3,2$ года). Самый младший пациент поступил в клинику через 4 часа после рождения. Отдаленный срок наблюдения составил от 2 месяцев до 10 лет.
У всех пациентов на момент поступления на ЭКГ была зафиксирована тахикардия с узкими комплексами QRS со средней частотой сокращения желудочков $210 \pm 35$ уд./мин. (от 140 до 280 уд./мин.). Тахикардия была верифицирована как трепетание предсердий после в/в струйного введения АТФ в дозе $0,1-0,3$ мг/кг. У $15(83,3 \%)$ пациентов наблюдалось АВ-проведение 2:1, у остальных - неправильное $\mathrm{AB}$-проведение.

Наиболее часто ТП возникало у новорожденных детей $-12(66,7 \%)$ пациентов. $6(33,3 \%)$ пациентов были госпитализированы в 1 -е сутки жизни, у 4 (22,2\%) из них диагноз был выставлен пренатально. Еще 4 $(22,2 \%)$ пациента были госпитализированы в возрасте до 6 месяцев, и только трое (16,7\%) были старше 1 года.

У одного ребенка $(5,6 \%)$ был диагностирован большой вторичный дефект межпредсердной перегородки. У остальных пациентов структурной патологии сердца выявлено не было.

У большинства детей ТП проявлялось бессимптомной ригидной тахикардией, которая выявлялась родителями или врачом при рутинном скрининговом обследовании. При этом у некоторых из них при эхокардиографическом обследовании (ЭхоКГ) было выявлено снижение сократительной функции левого желудочка (ЛЖ). У 6 (33,3\%) пациентов отмечались клинические проявления сердечной недостаточности (одышка, отеки, увеличение печени, полисерозит, артериальная гипотензия, рвота, нарушение пассажа по кишечнику, олигурия). В их числе были все пациенты старше 1 года. У двух пациентов с пренатально диа- 
гностированной аритмией, несмотря на проводимую антиаритмическую терапию, развилась водянка плода, что потребовало срочного родоразрешения путем кесарева сечения в сроке 36 и 38 недель.

Снижение сократительной функции ЛЖ (ФВ $<55 \%$, минимальная - 15\%) наблюдалось у 10 (55.6\%) пациентов, из них 4 были бессимптомными.

Результаты и обсуждение. У всех пациентов был восстановлен синусовый ритм путем медикаментозной или электрической кардиоверсии. У пациентов со стабильной гемодинамикой предпринималась попытка медикаментозного восстановления ритма, при нестабильной гемодинамике сразу выполнялась электроимпульсная терапия (ЭИТ). Все пациенты с сердечной недостаточностью получали соответствующую медикаментозную терапию (ингибиторы АПФ, диуретики).

У 10 (55,6\%) пациентов была выполнена медикаментозная кардиоверсия. Всем пациентам был назначен амиодарон в насыщающей дозе 15 мг/кг/сут. в/в в течение 3 дней с последующим переходом на поддерживающую дозу 5 мг/кг/сут. внутрь. У всех пациентов в течение 1 месяца наблюдения спонтанно восстановился синусовый ритм: у 3 из них - до 24 часов, у 2 - на 2-3-и сутки лечения. Более 3 суток терапия продолжалась только у бессимптомных пациентов. Трем пациентам, у которых в течение 3 суток не удалось достигнуть адекватной ЧСС, к терапии был добавлен дигоксин по быстрой схеме насыщения (30-40 мкг/кг/сут. в/в в течение суток, затем 10 мкг/кг/сут. внутрь в два приема) под контролем уровня дигоксина в сыворотке крови. У одного пациента дигоксин в терапевтической концентрации был неэффективен и заменен на метопролол в дозе 1 мг/кг/сут. внутрь.

У $5(27,8 \%)$ пациентов с клиническими проявлениями сердечной недостаточности или бессимптомным снижением функции ЛЖ после получения дозы насыщения амиодарона в течение 3 суток синусовый ритм не восстановился. Этим пациентам была выполнена плановая ЭИТ бифазным синхронизированным разрядом 0,5-1-2 Дж/кг.

У 3 (16,7\%) пациентов на момент поступления состояние было крайне тяжелым с нестабильной гемодинамикой. После в/в инфузии одной дозы амиодарона (5 мг/кг) этим пациентам выполнена ЭИТ, у всех восстановлен синусовый ритм. У одного ребенка потребовалась повторная ЭИТ в течение 24 часов в связи с рецидивом аритмии.

После восстановления синусового ритма всем пациентам была продолжена терапия амиодароном в течение одного месяца с последующей отменой препарата. У 2 (11,1\%) пациентов через 2 недели и 1 месяц после отмены соответственно возник рецидив аритмии. Антиаритмическая терапия у этих пациентов была возобновлена и продолжалась до 6 месяцев.
У одного $(5,6 \%)$ пациента после отмены амиодарона через 6 месяцев после дебюта аритмии вновь возник пароксизм ТП. Ребенку в возрасте 4 лет 9 месяцев (вес 18 кг) была выполнена успешная радиочастотная катетерная абляция кавотрикуспидального перешейка. Осложнений не было.

В настоящее время ни у одного пациента из группы наблюдения без антиаритмической терапии рецидива ТП нет. Сократительная функция ЛЖ восстановилась у всех пациентов.

\section{Выводы}

1. Трепетание предсердий - редко встречащееся у детей до 6 лет, но потенциально опасное нарушение ритма сердца, в большинстве случаев вызывающее снижение сократительной функции ЛЖ и клинические проявления сердечной недостаточности.

2. Стратегия восстановления и удержания синусового ритма у детей с трепетанием предсердий предпочтительна.

3. Амиодарон в качестве препарата первой линии у детей с ТП восстанавливает и удерживает ритм в подавляющем большинстве случаев.

4. У детей со стабильной гемодинамикой эффективна тактика медикаментозной или отсроченной электрической кардиоверсии.

5. У детей с рецидивирующим ТП на фоне антиаритмической терапии катетерная абляция достаточно безопасна и эффективна.

\section{Литература}

1. Pharmacological therapy in children with atrial fibrillation and atrial flutter / Fazio G., Visconti C., D’Angelo L. et al. // Curr Pharm Des. - 2008. - Vol. 14 (8). - P. 770-5.

2. Atrial Flutter in Infants / Texter K. M., Kertesz N. J., Friedman R. A. et al. // J Am CollCardiol. - 2006 Sep 5. Vol. 48 (5).- P. 1040-6.

3. Supraventricular tachycardia mechanisms and their age distribution in pediatric patients / Ko J., Deal B., Strasburger J. et al. // Am J Cardiol. - 2012. - Vol. 69. P. 1028-1032.

4. Pharmacological and non-pharmacological therapy for arrhythmias in the pediatric population: EHRA and AEPC Arrhythmia Working Group joint consensus statement / Brugada J., Blom N., Sarquella-Brugada G. et al. // Europace. - 2013. - Vol. 159. - P. 1337-1382.

5. Gupte S. Idiopathic Neonatal Atrial Flutter / Shilpa K., Kanade N., Pratap U. et al. // Pediatric Oncall Journal. 2016, January-March. - Vol. 13, № 1. Art \#14.

6. Atrial flutter and fibrillation in the young patient without congenital heart disease / S. Abadir, A. Fournier, M. Dubuc et al. // Progr in Ped Card. - 2013. - Vol. 35. - P. 41-48.

7. Лечение суправентрикулярной тахикардии у детей первого года жизни / Мешкова М. С., Доронин А. В., Ханенова В. А. и др. // Вісник серцево-судинної хірургіï. - 2016. - C. 76-77. 


\author{
Atrial flutter in young children \\ Meshkova M. ${ }^{1}$, Doronin A. ${ }^{2}$, Khanenova V. ${ }^{1}$, Rudenko N. ${ }^{2}$ \\ ${ }^{1}$ Ukrainian Children's Cardiac Center (Kyiv) \\ 2 Ukrainian National Medical Postgraduate Academy (Kyiv)
}

The article analyzes our own experience of treatment of atrial flutter in children of younger age (up to 6 years old).

The study group consisted of 18 consecutive patients. In all patients the sinus rhythm was restored with medication or electrical cardioversion. The medical cardioversion was performed in10 (55.6\%) patients, for $5(27.8 \%)$ patients we used delayed and for $3(16.7 \%)$ patients - urgent electric cardioversion. In $2(11.1 \%)$ patients there was a single recurrence of arrhythmia after the cancellation of antiarrhythmic therapy. In 1 (5.6\%) patient with repeatedly recurring arrhythmia at the age of 4 years 9 months (weight $18 \mathrm{~kg}$ ) we successfully performed a radiofrequency catheter ablation of the cava-tricuspid isthmus.

There were no complications of the treatment. At present, none of the patients in the study group have a recurrence of atrial flutterwithout antiarrhythmic therapy.

Key words:children, arrhythmias, atrial flutter, treatment.

\author{
Тріпотіння передсердь у дітей молодшого віку \\ Мешкова М. С. ${ }^{1}$, Доронін О. В. ${ }^{2}$, Ханенова В. А. ${ }^{1}$, Руденко Н. М. ${ }^{2}$ \\ ${ }^{1}$ ДУ «Науково-практичний медичний центр дитячої кардіології та кардіохірургії МОЗ України» (Київ) \\ ${ }^{2}$ Національна медична академія післядипломної освіти імені П. Л. Шупика (Київ)
}

У статті аналізується власний досвід лікування тріпотіння передсердь у дітей молодшого віку (до 6 років).

В досліджувану групу ввійшли 18 послідовних пацієнтів. У всіх пацієнтів був відновлений синусовий ритм шляхом медикаментозної або електричної кардіоверсії. У $10(55,6 \%)$ пацієнтів була виконана медикаментозна кардіоверсія, у $5(27,8 \%)$ - відстрочена і у $3(16,7 \%)$ - термінова електроімпульсна терапія. У $2(11,1 \%)$ пацієнтів виник одноразовий рецидив аритмії після скасування антиаритмічної терапії. В одного $(5,6 \%)$ пацієнта 3 неодноразовими нападами аритмії у віці 4 років 9 місяців (вага 18 кг) була виконана успішна радіочастотна катетерна абляція кавотрикуспідального перешийка.

Ускладнень лікування не було. Наразі у жодного пацієнта з групи спостереження без антиаритмічної терапії рецидиву ТП немає.

Ключові слова: діти, аритмії, тріпотіння передсердь, лікування. 